\title{
Os depósitos tecnogênicos construídos no mapeamento geológico de planícies costeiras: o caso da Ilha de Santa Catarina, Santa Catarina, Brasil
}

\author{
The built technogenic deposits on the geologic mapping of the coastal \\ plains: the case of Santa Catarina Island, Santa Catarina, Brazil
}

\section{Marinês da Silva $^{\text {ab }}$, Norberto Olmiro Horn Filho ${ }^{\text {ac }}$}

\author{
${ }^{a}$ Universidade Federal de Santa Catarina, UFSC

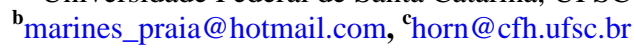

\begin{abstract}
RESUMO
Este trabalho apresenta os resultados de uma pesquisa acerca de depósitos tecnogênicos na Ilha de Santa Catarina, Santa Catarina, Brasil, onde foram aplicadas técnicas de mapeamento geológico e de sedimentologia. O objetivo principal consistiu em estudar os aspectos geológicos e geomorfológicos desses depósitos. Dentre os procedimentos metodológicos empregados estão revisão cartográfica; análise de imagens aéreas para a seleção dos pontos que foram visitados no trabalho de campo; coleta de sedimentos dos depósitos estudados; análise textural dos sedimentos e geoprocessamento que resultou na construção dos mapas geológicos. Os resultados incluem o mapeamento geológico e a caracterização dos depósitos tecnogênicos na Ilha de Santa Catarina e a visibilidade das intensas transformações no ambiente geológico-geomorfológico provocadas pela ação antrópica.
\end{abstract}

Palavras-chave: planície costeira; Ilha de Santa Catarina; área antropizada; Depósito Tecnogênico.

\begin{abstract}
This work presents the results from a survey about technogenic deposits on the Santa Catarina Island, Santa Catarina, Brazil, where techniques of geological mapping and sedimentology were applied. The main objective consisted in studying the geological and geomorphological aspects of these deposits. Among the methodological procedures employed are cartographic review; analysis of aerial images for the selection of the points that were visited during the fieldwork; sampling of sediment of the studied deposits; textural analyses of the sediments and geoprocessing that resulted in the construction of the geologic maps. The results include the geological mapping and characterization of technogenic deposits on the Santa Catarina Island and the visibility about the intense transformations in geological and geomorphologic environment caused by human action.
\end{abstract}

Keywords: coastal plain; Santa Catarina Island; anthropic area; Technogenic Deposit.

\section{Introdução}

A Ilha de Santa Catarina corresponde à porção insular do município de Florianópolis, capital do estado de Santa Catarina, localizado na região Sul do Brasil (figura 1).

Para efeitos de conceituação, este trabalho considerou como Depósito Tecnogênico Construído o depósito natural que sofreu remobilização antrópica com uso de tecnologias (como por exemplo, dragas, escavadeiras ou tratores), formando assim um novo depósito (Silva 2013). O quadro 1 aborda as classificações dos depósitos tecnogênicos com base em Fanning \& Fanning (1989), Oliveira (1990) e Nolasco (2002).

O surgimento de depósitos tecnogênicos na ilha teve início em 1958, quando o incinerador de resíduos sólidos não era mais capaz de atender à população de pouco mais de 70.000 habitantes, surgindo assim o
Depósito Tecnogênico Gárbico sobre o Manguezal do Itacorubi.

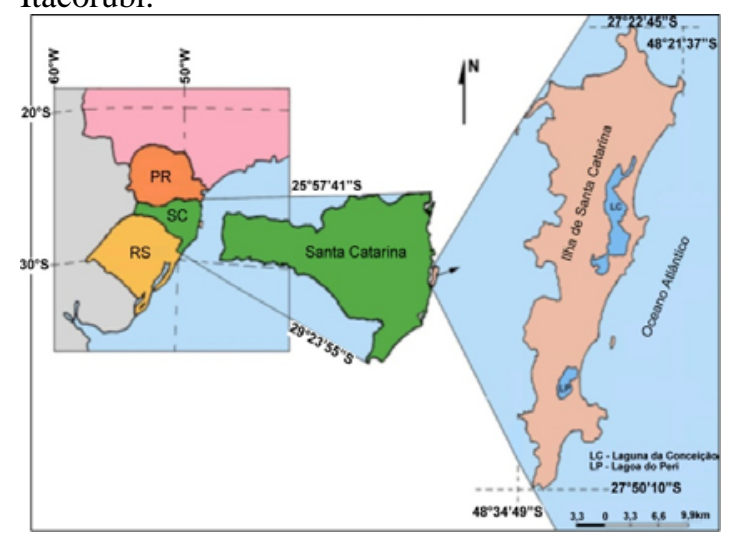

Figura 1: Mapa de localização da Ilha de Santa Catarina (Horn Filho et al. 2013).

Com o passar dos anos, o crescimento demográfico trouxe a necessidade de ampliação do sistema viário, o 
Antropoceno - Tecnógeno

que culminou na construção dos aterros hidráulicos sobre as baías Norte e Sul - depósitos tecnogênicos dragados - nas décadas de 1970, 1980 e 1990.

Recentemente, erosão costeira provocada por ressacas danificaram residências construídas inadequadamente sobre dunas frontais na praia da Armação, e a resposta emergencial dada pelo poder público foi a instalação de um Depósito Tecnogênico Espólico.

Quadro 1: Classificação de depósitos tecnogênicos com base em diferentes autores.

\begin{tabular}{|c|c|c|}
\hline Autor & Depósito Tecnogênico & Exemplo \\
\hline \multirow{4}{*}{$\begin{array}{l}\text { Fanning \& Fanning (1989) apud } \\
\text { Peloggia (1998a) }\end{array}$} & Gárbico & Lixões e aterros sanitários \\
\hline & Úrbico & Detritos urbanos como materiais de demolições \\
\hline & Espólico & Material proveniente de terraplanagem \\
\hline & Dragado & Material dragado de cursos d'água ou fundo marinho \\
\hline \multirow{3}{*}{$\begin{array}{c}\text { Oliveira (1990) apud Oliveira et } \\
\text { al. (2005) }\end{array}$} & Construído & Aterros \\
\hline & Induzido & Material oriundo de erosão após uso do solo e/ou desmatamento \\
\hline & Modificado & Material alterado por efluentes e adubos \\
\hline \multirow{3}{*}{$\begin{array}{c}\text { Nolasco (2002) apud Oliveira et } \\
\text { al. (2005) }\end{array}$} & \multirow[t]{2}{*}{ Construído } & Aterros \\
\hline & & $\begin{array}{l}\text { Depósitos provenientes de escorregamentos em minerações (uso } \\
\text { planejado) }\end{array}$ \\
\hline & Indireto & $\begin{array}{l}\text { Depósitos gerados com o escorregamento de encostas a partir da } \\
\text { ocupação }\end{array}$ \\
\hline
\end{tabular}

O mesmo autor considerou a atividade antrópica um poderoso "fator geológico" na sedimentação e no transporte de material na superfície da Terra, assim como Oliveira et al. (2005) afirmando que se os ambientes geológicos estão associados a agentes como o vento, o gelo e a água, os ambientes transformados pela ação antrópica conferem ao homem a qualidade de agente geológico e geomorfológico.

Tem sido discutido o reconhecimento estratigráfico e cronológico dos depósitos tecnogênicos como unidade geológica ou litoestratigráfica diferenciada das unidades naturais e relacionada a um tempo geológico próprio, o Quinário ou Tecnógeno. O tema foi explorado por Peloggia (1995, 1997, 2003), sendo sua proposta a inclusão dos depósitos tecnogênicos como uma categoria de unidade litoestratigráfica especial. Os argumentos que vão ao encontro dessa perspectiva são a rapidez e a intensidade das modificações humanas na natureza em comparação com as ações naturais. Processos naturais que se realizariam em alguns mil anos - como por exemplo, uma praia - podem ser criados artificialmente pelo homem em poucos meses. Conforme destacaram Oliveira et al. (2005), apesar da recente existência do homem, a intensidade de suas ações e seus efeitos frequentemente superam os equivalentes naturais.

Outras áreas do conhecimento também têm considerado o homem um agente modificador devido à significativa diferenciação produzida no meio
Os depósitos tecnogênicos da Ilha de Santa Catarina ainda não haviam sido descritos ou mapeados, com exceção dos depósitos tecnogênicos dragados mapeados por Lisbôa (2004). As transformações geológico-geomorfológicas em consequência da instalação dos depósitos artificialmente construídos no mundo apontam para a importância de seu mapeamento, conforme destacou Chemekov (1983) que num futuro próximo seria necessário mapear os depósitos tecnogênicos. 
Antropoceno - Tecnógeno

seleção dos pontos amostrais que foram visitados no trabalho de campo.

O trabalho de campo foi realizado nos dias 4 e 5 de dezembro de 2012, foram coletadas amostras de sedimentos tecnogênicos (TEC 01, 02, 03 e 04) e naturais (NAT 01, 02, 03 e 04) extraindo-se suas coordenadas com uso do Global Positioning System GPS para compor o mapa de pontos amostrais (quadro 2, figura 2).

Quadro 2: Depósitos tecnogênicos e depósitos naturais correlatos.

\begin{tabular}{ccc}
\hline Amostra & $\begin{array}{c}\text { Depósito } \\
\text { Tecnogênico }\end{array}$ & Depósito natural \\
\hline TEC 01 & Gárbico & - \\
NAT 01 & - & Paludial \\
TEC 02 & Úrbico & - \\
NAT 02 & - & Colúvio-aluvionar \\
TEC 03 & Dragado & - \\
NAT 03 & - & Fundo de baía \\
TEC 04 & Espólico & - \\
NAT 04 & - & Marinho Praial \\
\hline
\end{tabular}

Os sedimentos naturais - que não sofreram transporte, deposição ou alteração pela ação antrópica representavam as condições geológicas dos locais de atual deposição tecnogênica antes da deposição. Portanto, sobre os depósitos chamados "naturais" (NAT), foram depositados os depósitos tecnogênicos (TEC), restando áreas adjacentes com características geológicas preservadas. A partir da comparação entre o depósito artificializado (TEC) e depósito inalterado (NAT) correlato foi possível analisar as mudanças causadas na sedimentologia a partir da ação do homem.

Após o trabalho de campo, as coordenadas dos pontos visitados foram transferidas para o software ArcGIS 10.0 para confecção dos mapas. Durante os meses de dezembro de 2012 e janeiro de 2013, as amostras coletadas foram processadas no Laboratório de Sedimentologia do Departamento de Geociências da Universidade Federal de Santa Catarina.

A análise constou de lavagem das amostras com água destilada para a retirada dos sais solúveis, secagem em estufa a $60^{\circ} \mathrm{C}$ e quarteamento para obtenção de porções de 30g. A queima da matéria orgânica (MO) foi realizada utilizando-se mufla para as amostras TEC 01, NAT 01, TEC 02 e NAT 02 pela abundância em MO, e o reagente peróxido de hidrogênio $\left(\mathrm{H}_{2} \mathrm{O}_{2}\right)$ nas amostras TEC 03, NAT 03, TEC 04 e NAT 04. Procedeu-se também à queima do carbonato de cálcio $\left(\mathrm{CaCO}_{3}\right) \mathrm{com}$ ácido clorídrico $(\mathrm{HCl})$.

Realizou-se o peneiramento das amostras e os dados obtidos foram processados no software Sysgran 3.0 (Camargo 1997) que determinou o percentual de cada tamanho de grão (cascalho, areia e finos) em cada amostra (quadro 3), tomando-se como base a escala granulométrica de Wentworth (1922).

\section{Resultados}

A instalação de depósitos tecnogênicos na Ilha de Santa Catarina acarretou em diversas alterações do ponto de vista geológico e geomorfológico. Essas modificações são evidenciadas através de dados granulométricos, topográficos, imagéticos e espaciais.

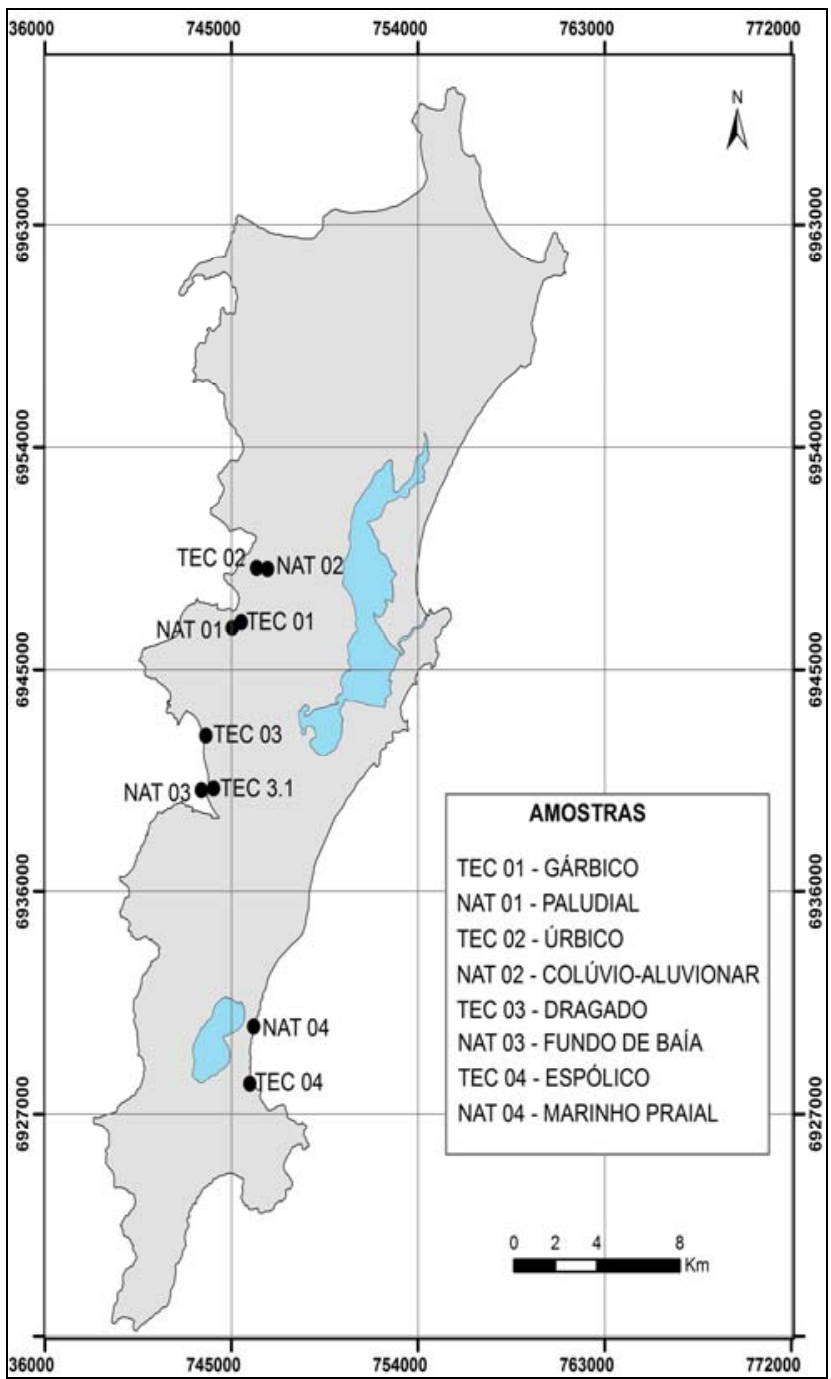

Figura 2: Mapa de pontos amostrais obtidos na Ilha de Santa Catarina Quadro 3: Porcentagem das classes granulométricas.

\begin{tabular}{cccc}
\hline Amostra & \% Cascalho & \% Areia & \% Finos \\
\hline TEC 01 & 36,35 & 61,72 & 1,93 \\
NAT 01 & 4,20 & 91,73 & 4,07 \\
TEC 02 & 49,26 & 49,26 & 1,48 \\
NAT 02 & 5,61 & 91,51 & 2,88 \\
TEC 03 & 0,00 & 99,78 & 0,22 \\
NAT 03 & 0,00 & 99,4 & 0,60 \\
TEC 04 & 58,11 & 41,35 & 0,54 \\
NAT 04 & 0,00 & 100 & 0,00 \\
\hline
\end{tabular}

Com relação aos aspectos texturais é notável o distanciamento entre os depósitos tecnogênicos construídos (TEC) e seus depósitos naturais correlatos (NAT), conforme expõe o quadro 3. Em três dos quatro pontos estudados houve aumento dos percentuais de cascalho (TEC 01, TEC 02 e TEC 04), levando 
Antropoceno - Tecnógeno

inclusive à mudança de classificação textural de areia para cascalho, no caso da amostra TEC 04.

O aumento de sedimentos cascalhosos se deu pela introdução de fragmentos artificiais de diversas fontes e origens, incluindo fragmentos de rochas, restos úrbicos e rejeitos da construção civil. As cores dos sedimentos também foram alteradas, conforme mostram as imagens comparativas presentes nas figuras 5, 6, 7 e 8 .

O quadro 4 relaciona os depósitos tecnogênicos com as respectivas obras que os geraram, trazendo as altitudes médias dos depósitos.

Quadro 4: Depósitos tecnogênicos construídos (com base em Fanning \& Fanning 1989) na Ilha de Santa Catarina e seus depósitos naturais correlatos.

\begin{tabular}{|c|c|c|c|c|}
\hline Ponto & Depósito & Local & Altitude (m) & Obra \\
\hline TEC 01 & Tecnogênico Gárbico & \multirow{2}{*}{ Itacorubi } & 11 & Lixão \\
\hline NAT 01 & Paludial & & 7 & - \\
\hline TEC 02 & Tecnogênico Úrbico & \multirow{2}{*}{ Monte Verde } & 11 & Aterro de Inertes \\
\hline NAT 02 & Colúvio-aluvionar & & 6 & - \\
\hline TEC 03 & Tecnogênico Dragado & Costeira do Pirajubaé & 2 & Aterro hidráulico \\
\hline NAT 03 & Fundo de Baía & Baía Sul & 0 & - \\
\hline TEC 04 & Tecnogênico Espólico & \multirow{2}{*}{ Praia da Armação } & 2 & Obra de contenção marinha \\
\hline NAT 04 & Marinho Praial & & 1 & - \\
\hline
\end{tabular}

É possível constatar a deposição de material tecnogênico sobre os depósitos naturais a partir do aumento das altitudes, tendo destaque os pontos TEC 01 e TEC 02 com alterações topográficas de 5 e 4m, respectivamente.

As figuras 5, 6, 7 e 8 permitem observar as alterações geomorfológicas provocadas pela tecnogênese.

O Depósito Tecnogênico Gárbico (figura 5A) originou nova forma de relevo semelhante a uma rampa coluvial, onde originalmente havia uma planície de maré com presença do ecossistema de manguezal, tal como é a área adjacente apresentada na figura 5C.

$\mathrm{Na}$ figura 6A está apresentado o Depósito Tecnogênico Úrbico formando montes de deposição que descaracterizam o relevo original. As figuras 6B (TEC 02) e 6C (NAT 02) apresentam os sedimentos com detalhe, onde é perceptível sua diferenciação.

Com relação ao Depósito Tecnogênico Dragado, houve a construção de uma planície costeira sobre a baía (figura 5A). As figuras 7B e 7C expõem as amostras TEC 03 e NAT 03 respectivamente, que não apresentam grandes modificações texturais pelo fato dos tecnogênicos terem sido dragados do banco arenoso da própria baía. O Depósito Tecnogênico Espólico (figura 8A) acarretou no surgimento de uma feição geomorfológica que se assemelha a um terraço marinho. Foi drástica a transformação granulométrica provocada por essa deposição, mostrada nas figuras 8B (TEC 04) e 8D (NAT 04).

As transformações trazidas pelos depósitos tecnogênicos na Ilha de Santa Catarina são ainda expostas espacialmente nas figuras 3 e 4 . O mapa de depósitos tecnogênicos e áreas antropizadas da Ilha de
Santa Catarina (figura 3) traz a localização e delimitação dos depósitos tecnogênicos estudados e de dois outros depósitos tecnogênicos dragados não contemplados pelo trabalho de campo e análise granulométrica, os aterros das baías Norte e Sul. Também estão presentes as áreas antropizadas da ilha, definidas por Silva (2006) como áreas que tiveram suas características físicas originais alteradas em função da urbanização.

O mapa geológico da planície costeira da Ilha de Santa Catarina (figura 4) incluiu como unidade litoestratigráfica o depósito tecnogênico que se encontra associado principalmente aos depósitos costeiros. Da mesma forma estão as áreas antropizadas, revelando o interesse da sociedade em ocupar prioritariamente áreas costeiras.

\section{Conclusão}

A finalização deste trabalho resultou num estudo geológico e geomorfológico acerca da instalação de depósitos tecnogênicos na Ilha de Santa Catarina.

Permitiu evidenciar a descaracterização da geologia e da geomorfologia costeira da ilha pela implantação de depósitos tecnogênicos e com isso a importância de seu mapeamento e consideração como unidade estratigráfica.

Entretanto, muito trabalho ainda há de ser feito, pois se percebe a escassez de mapeamentos desse depósito e a necessidade de uniformização da linguagem e dos conceitos acerca dos depósitos tecnogênicos. 
Antropoceno - Tecnógeno

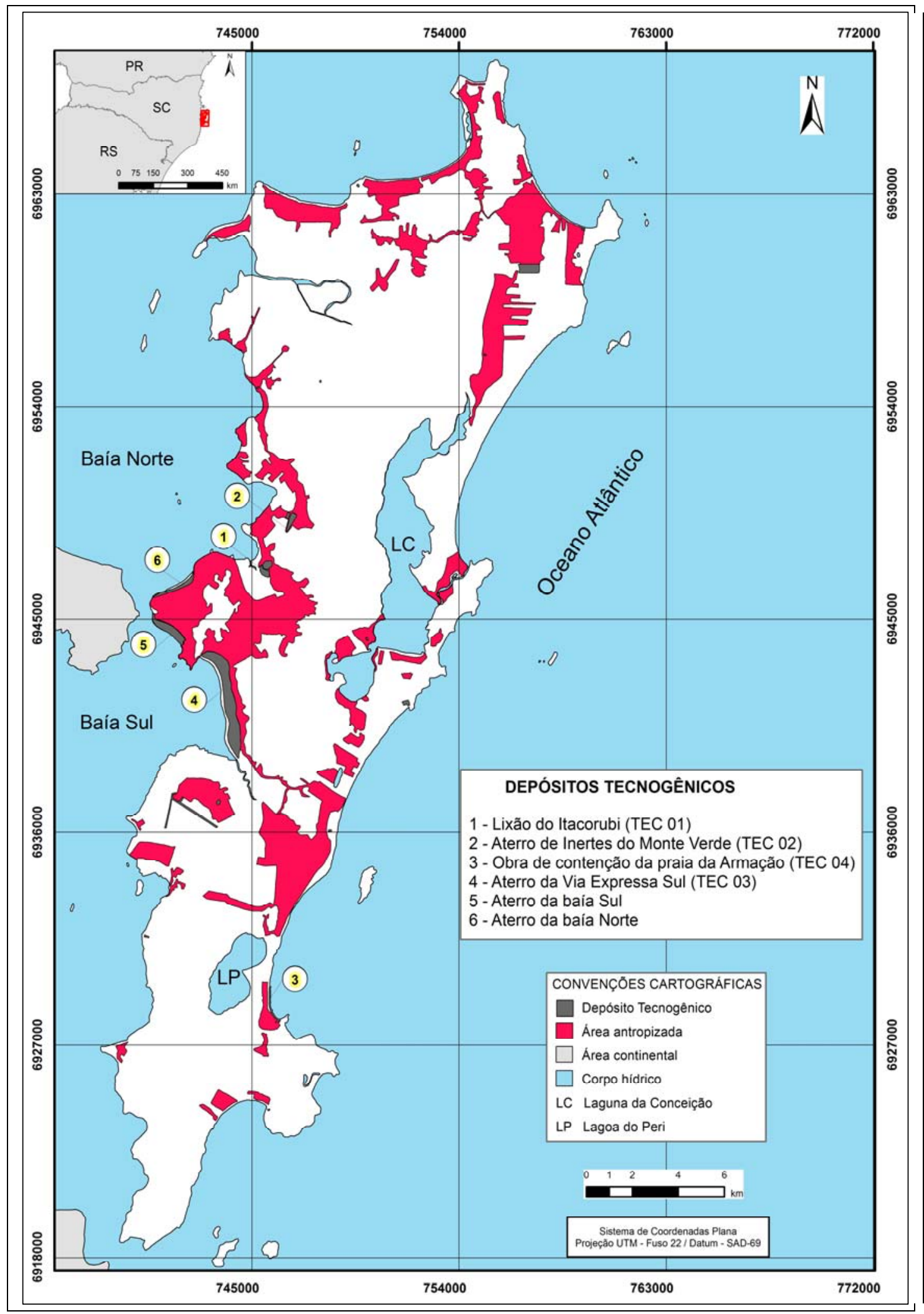

Figura 3: Mapa dos depósitos tecnogênicos da Ilha de Santa Catarina e áreas antropizadas. 
Antropoceno - Tecnógeno

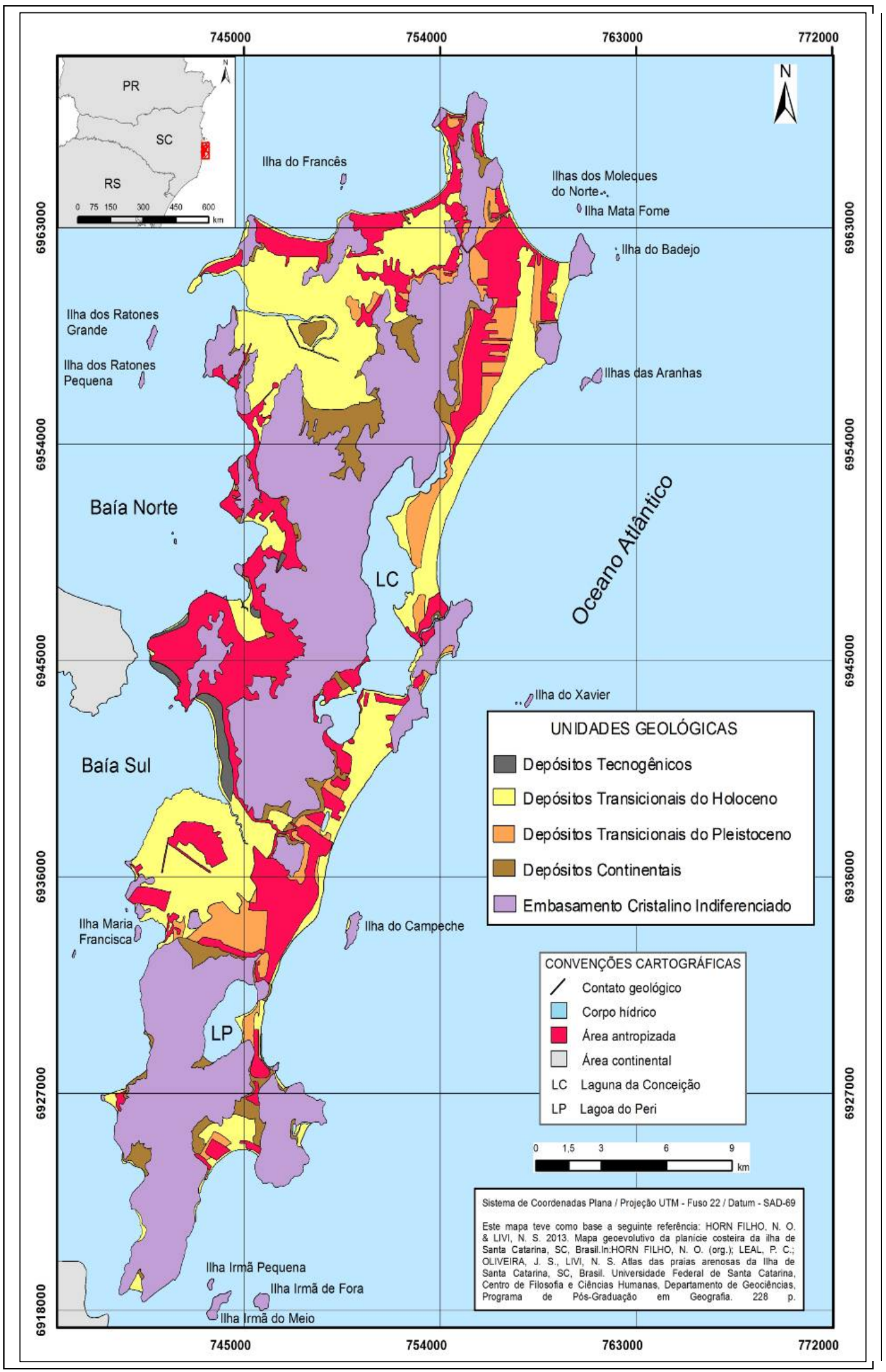

Figura 4: Mapa geológico da planície costeira da Ilha de Santa Catarina. 


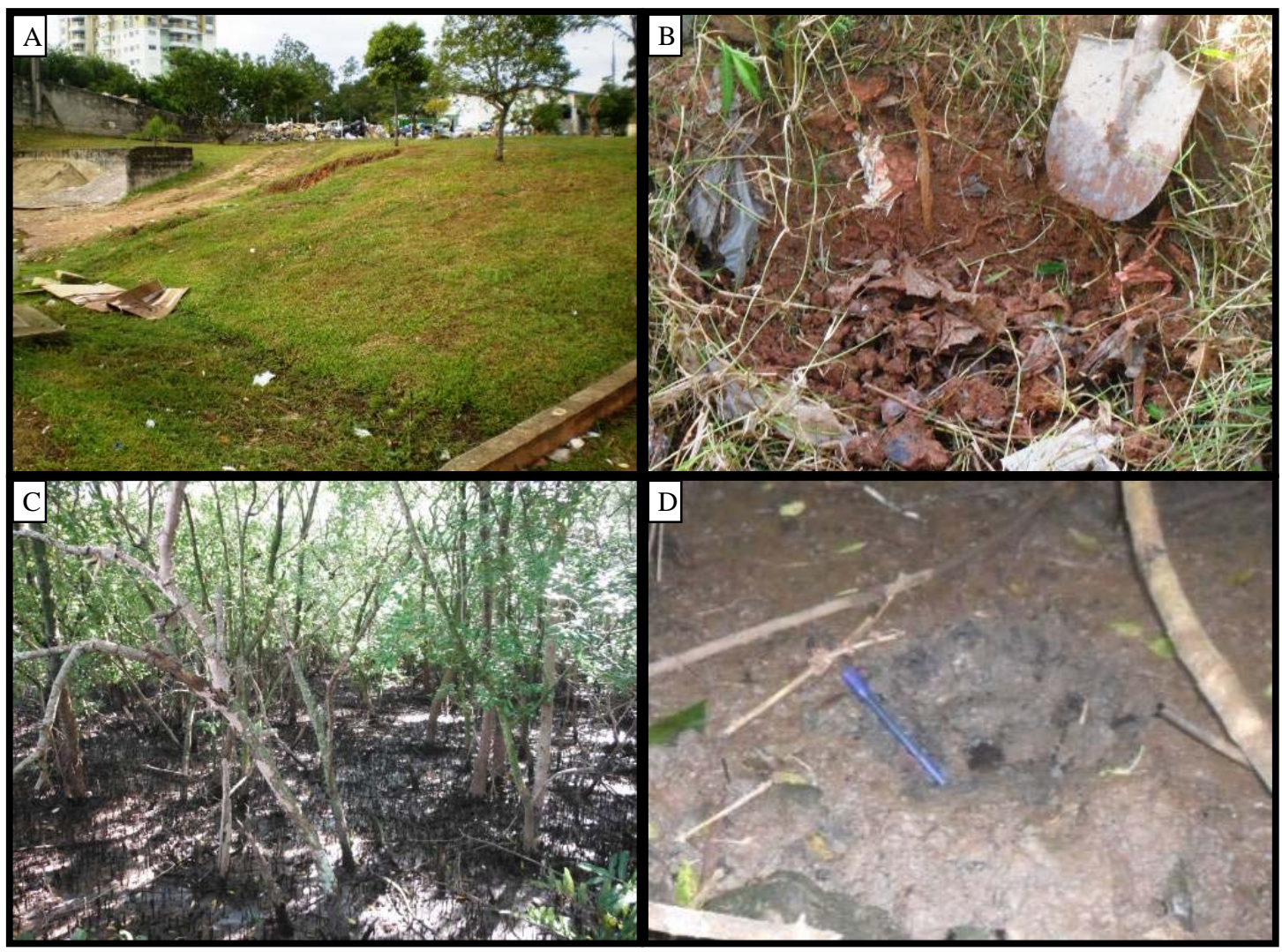

Figura 5: A) Depósito Tecnogênico Gárbico do Lixão do Itacorubi; B) Local de coleta da amostra TEC 01; C) Manguezal do Itacorubi com espécies vegetais típicas; D) Local de coleta da amostra NAT 01 (Fotos: Marinês da Silva, dezembro de 2012).

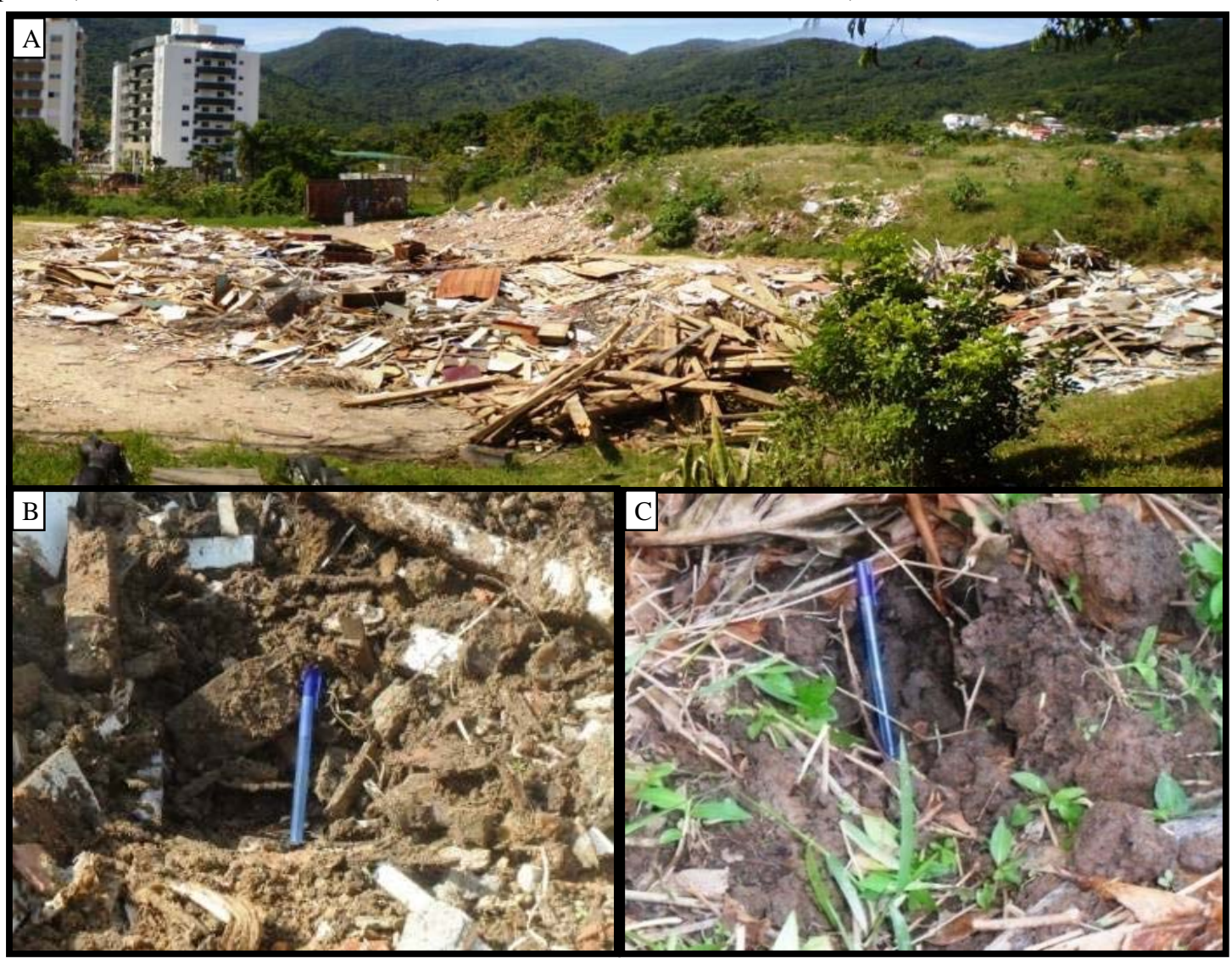

Figura 6: A) Vista para nordeste do Aterro de Inertes; B) Local de coleta da amostra TEC 02; C) Local de coleta da amostra NAT 02 (Fotos: Marinês da Silva, dezembro de 2012). 
Antropoceno - Tecnógeno

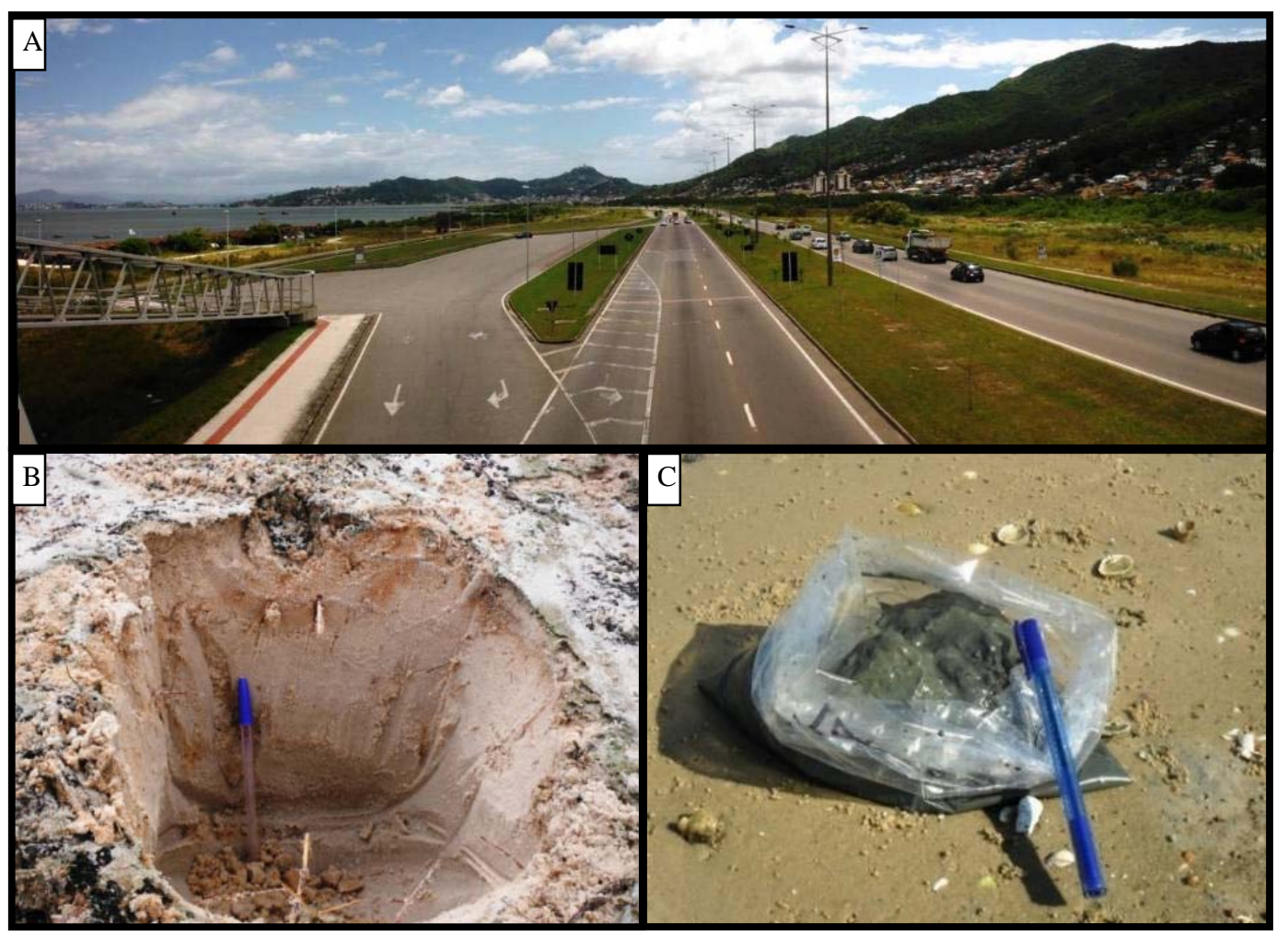

Figura 7: A) Vista para norte do Depósito Tecnogênico Dragado implantado entre a baía Sul (à esquerda) e Maciço da Costeira (à direita); B) Local de coleta da amostra TEC 03; C) Local de coleta da amostra NAT 03 após coleta (Fotos: Marinês da Silva, dezembro de 2012).

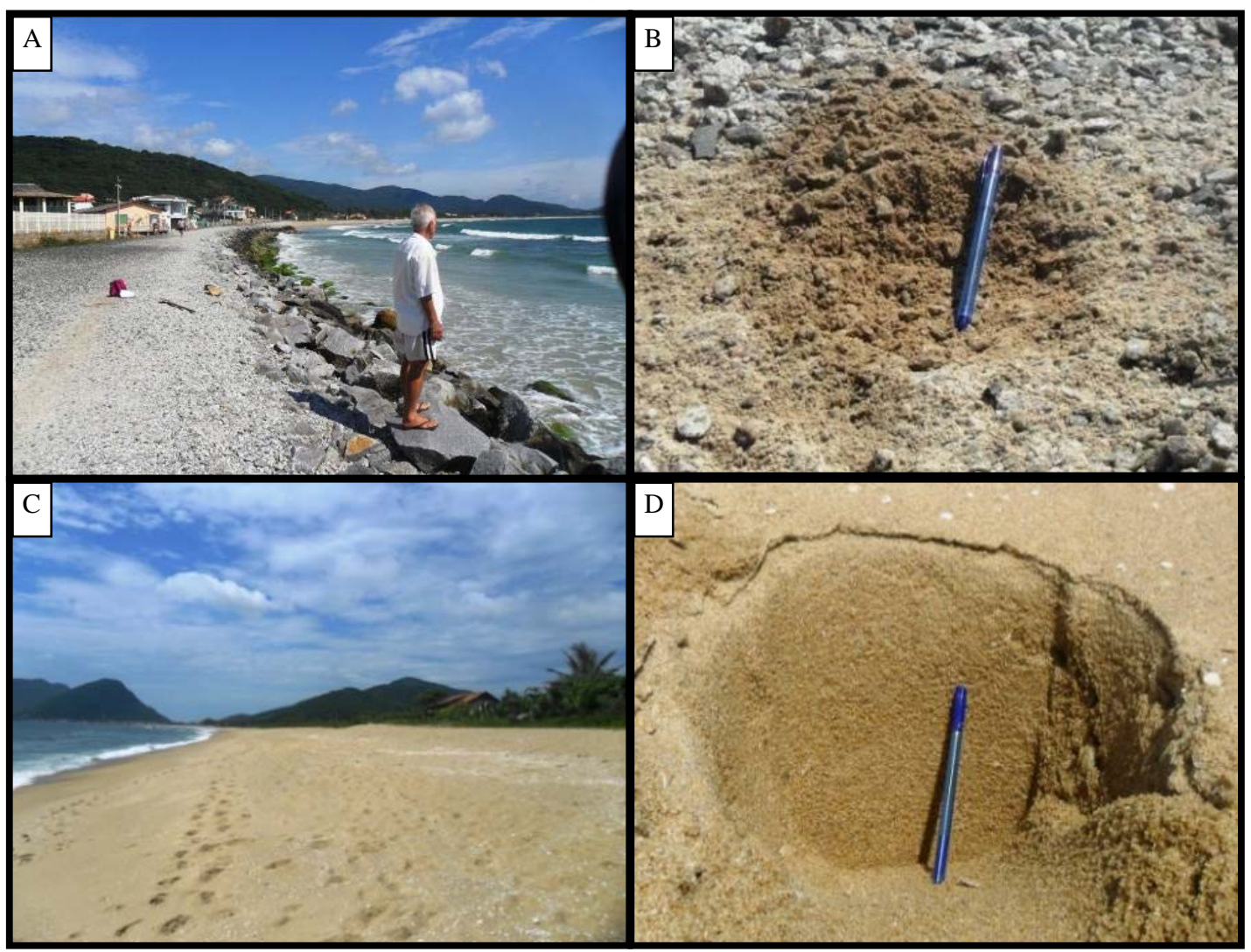

Figura 8: A) Vista para noroeste expondo a obra de contenção da praia da Armação; B) Local de coleta da amostra TEC 04; C) Vista para sul da praia da Armação; D) Local de coleta da amostra NAT 04 (Fotos: Marinês da Silva, dezembro de 2012).

\section{Referências}

Camargo M.G. 1997. SYSGRAN para Windows: sistema de análises granulométricas. Versão 3.0 .
Caruso Junior F. 1993. Texto explicativo de mapa geológico da Ilha de Santa Catarina. Porto Alegre: UFRGS/PETROBRÁS, 28p. Chemekov Y.F. 1983. Technogenic deposits. In: XI INQUA Congress, 3, Moscow. Abstracts... p. 62. 
Curcio G.R., Lima V.C., Giarola N.F.B. 2004. Antropossolos: proposta de ordem ( $1^{\mathrm{a}}$ aproximação). Colombo, PR: EMBRAPA Florestas, 49p.

EPAGRI - Empresa de Pesquisa Agropecuária e Extensão Rural de Santa Catarina. 2012. Mapas digitais de Santa Catarina. Disponível em: <http://ciram.epagri.sc.gov.br/mapoteca/> Acesso em: março 2012.

Fanning D.J., Fanning M.C.B. 1989. Soil: morphology, genesis and classification. New York: John Wiley \& Sons. 395p.

Horn Filho N.O., Leal P.C., Oliveira J.S., Livi N.S. (Org.). 2013. Atlas das praias arenosas da Ilha de Santa Catarina, SC, Brasil. Florianópolis: Programa de Pós-Graduação em Geografia, Universidade Federal de Santa Catarina, 228 p.

Horn Filho N.O., Livi N.S. 2013. Mapa geoevolutivo da planície costeira da Ilha de Santa Catarina, SC, Brasil. In: Horn Filho N.O., Leal P.C., Oliveira J.S., Livi N.S. (Org.). 2013. Atlas das praias arenosas da Ilha de Santa Catarina, SC, Brasil. Florianópolis: Programa de Pós-Graduação em Geografia, Universidade Federal de Santa Catarina, p.224.

Lisbôa T.H.C. 2004. Os depósitos tecnogênicos e a alteração da linha de costa do Distrito Sede de Florianópolis/SC. Dissertação (Mestrado em Geografia) - Centro de Filosofia e Ciências Humanas, Universidade Federal de Santa Catarina, Florianópolis, 96p..

Nolasco M.C. 2002. Registros geológicos deixados pelo garimpo. Lavras Diamantinas - BA. Tese (Doutorado em Geociências) Universidade Federal do Rio Grande do Sul, Porto Alegre. 355p.

Oliveira A.M.S. 1990. Depósitos tecnogênicos associados à erosão atual. In: Congresso Brasileiro de Engenharia, 6, Salvador. Atas... ABGE, 1:411-415.

Oliveira A.M.S., Brannstrom C., Nolasco M.C., Peloggia A.U.G., Peixoto M.N. de O., Coltrinari L. 2005. Tecnógeno: registros da ação geológica do homem. In: Souza C.R.G., Suguio K., Oliveira A.M.S., Oliveira P.E. de (Org.). Quaternário do Brasil. Ribeirão Preto: Holos, p. 363-376.

Peloggia A.U.G. 1995. Discussão do artigo “A teoria e a prática em Geografia e o eterno retorno”, de Carneiro et al. (1993), em alguns aspectos selecionados. Revista Brasileira de Geociências 25(3):206-208.

Peloggia A.U.G. 1997. A ação do homem enquanto ponto fundamental da Geologia do Tecnógeno: proposição teórica básica e discussão acerca do caso do município de São Paulo. Revista Brasileira de Geociências 27(3): 257-268.

Peloggia A.U.G. 1998. O homem e o ambiente geológico. São Paulo: Xamã.

Peloggia A.U.G. 2003. O problema estratigráfico dos depósitos tecnogênicos. In: Congresso Brasileiro de Estudos do Quaternário, 9, Recife. Anais... ABEQUA (CD-ROM), 5p.

Pelloggia A.U.G., Oliveira A.M.S. 2005. Tecnógeno: um novo campo de estudos das Geociências. In: Congresso da Associação Brasileira de Estudo do Quaternário, 10, Guarapari. Anais... ABEQUA (CD-ROM).

Silva I.M.P.F. 2006. Impactos socioambientais da implantação de linha de transmissão de energia elétrica sobre as comunidades extrativistas de babaçu no estado do Maranhão. Dissertação (Mestrado) - Universidade Federal de Pernambuco, Recife, $103 p$.

Silva M. 2013. Impactos ambientais decorrentes da instalação de depósitos tecnogênicos na Ilha de Santa Catarina, SC, Brasil. SC. Dissertação (Mestrado em Geografia) - Universidade Federal de Santa Catarina, Florianópolis, 89p..

Szabó J., Dávid L., Lóczy D. 2010. Anthropogenic Geomorphology: A Guide to Man-Made Landforms. Dordrecht: Springer, 298p.

Wentworth C.K. 1922. A scale of grade and class terms for clastic sediments. Journal of Geology, 30: 377-392 